\title{
Review of NASA In-Space Propulsion Technology Program Inflatable Decelerator Investments
}

\author{
Erin H. Richardson", Michelle M. Munk ${ }^{\dagger}$, Bonnie F. James ${ }^{\ddagger}$ \\ NASA, Marshall Space Flight Center, Huntsville, AL, 35812 \\ Steve A. Moon ${ }^{\S}$ \\ Gray Research, 655 Discovery Drive Huntsville, AL 35806
}

\begin{abstract}
The NASA In-Space Propulsion Technology (ISPT) Program is managed by the NASA Headquarters Science Mission Directorate and is implemented by the Marshall Space Flight Center in Huntsville, Alabama. The ISPT objective is to fund development of promising inspace propulsion technologies that can decrease flight times, decrease cost, or increase delivered payload mass for future science missions. Before ISPT will invest in a technology, the Technology Readiness Level (TRL) of the concept must be estimated to be at TRL 3. A TRL 3 signifies that the technical community agrees that the feasibility of the concept has been proven through experiment or analysis. One of the highest priority technology investments for ISPT is Aerocapture. The aerocapture maneuver uses a planetary atmosphere to reduce or alter the speed of a vehicle allowing for quick, propellantless (or using very little propellant) orbit capture. The atmosphere is used as a brake, transferring the energy associated with the vehicle's high speed into thermal energy. The ISPT Aerocapture Technology Area (ATA) is currently investing in the development of advanced lightweight ablative thermal protection systems, high temperature composite structures, and heat-flux sensors for rigid aeroshells. The heritage of rigid aeroshells extends back to the Apollo era and this technology will most likely be used by the first generation aerocapture vehicle. As a second generation aerocapture technology, ISPT is investing in three inflatable aerodynamic decelerator concepts for planetary aerocapture. They are: trailing ballute (balloon-parachute), attached afterbody ballute, and an inflatable aeroshell. ISPT also leverages the NASA Small Business Innovative Research Program for additional inflatable decelerator technology development. In mid-2004 ISPT requested an independent review of the three inflatable decelerator technologies funded directly by ISPT to validate the TRL and to identify technology maturation concerns. An independent panel with expertise in advanced thin film materials, aerothermodynamics, trajectory design, and inflatable structures was convened to assess the ISPT investments. The panel considered all major technical subsystems including materials, aerothermodynamics, structural dynamics, packaging, and inflation systems. The panel assessed the overall technology readiness of inflatable decelerators to be a 3 and identified fluid-structure interaction, aeroheating, and structural adhesives to be of highest technical concern.
\end{abstract}

\section{Introduction}

$\mathrm{N}$ ASA's In-Space Propulsion Technology Program is investing in technologies that have the potential to revolutionize the robotic exploration of deep space. At the program's inception, a set of technology investment priorities were established using an Agency-wide prioritization process and has changed little thus allowing a consistent framework in which to fund and manage technology development. High-priority technologies are those

- Assistant Manager, Aerocapture Technology, In-Space Propulsion Technology Project, NP40

${ }^{\dagger}$ Lead Technologist, Aerocapture Technology, In-Space Propulsion Project, NP40, Senior Member AIAA

${ }^{\ddagger}$ Manager, Aerocapture Technology, In-Space Propulsion Technology Project, NP40

$\S$ Systems Engineer, In-Space Propulsion, Gray Research, Inc., Huntsville, AL

1

American Institute of Aeronautics and Astronautics 
considered enabling for a set of high-value midterm science targets. Medium-priority technologies are those that will enhance or enable missions that are not perceived as critical as those benefiting from the high-priority technologies, but are still important and need significant funding.

The scope of ISP Technology development begins at Technology Readiness Level (TRL) 3 and continues until a TRL of 6 where that is possible, through ground, or, if appropriate, flight demonstrations. Table 2 provides Technology Readiness Level definitions.

Table 1. Technology Readiness Level Definitions

\begin{tabular}{|c|c|}
\hline $\begin{array}{c}\text { Technical } \\
\text { Readiness Level }\end{array}$ & Definitions \\
\hline TRL 1 & Basic principles observed and reported \\
\hline TRL 2 & Technology concept or application formulated \\
\hline TRL 3 & $\begin{array}{c}\text { Analytical and experimental critical function or } \\
\text { characteristic proof-of-concept }\end{array}$ \\
\hline TRL 4 & $\begin{array}{c}\text { Component or breadboard validation in laboratory } \\
\text { environment }\end{array}$ \\
\hline TRL 5 & $\begin{array}{c}\text { Component or breadboard validation in relevant } \\
\text { environment }\end{array}$ \\
\hline TRL 6 & $\begin{array}{c}\text { System/subsystem model or prototype demonstration in } \\
\text { a relevant environment (ground or space) }\end{array}$ \\
\hline TRL 7 & $\begin{array}{c}\text { System prototype demonstration in a space } \\
\text { environment }\end{array}$ \\
\hline TRL 8 & $\begin{array}{c}\text { Actual system completed and "flight-qualified" } \\
\text { through test and demonstration (ground or space) }\end{array}$ \\
\hline TRL 9 & $\begin{array}{c}\text { Actual system "flight-proven" through successful } \\
\text { mission operations }\end{array}$ \\
\hline
\end{tabular}

\section{Aerocapture}

Aerocapture uses a planet's atmosphere to accomplish a quick, near-propellantless orbit capture-the placement of a space vehicle in its proper orbit. The atmosphere is used as a brake to slow down a spacecraft, transferring the energy associated with the vehicle's high speed into thermal energy.

The aerocapture maneuver starts with a hyperbolic trajectory into the atmosphere of the target body. The atmosphere's density creates friction, slowing the craft and allowing it to be captured into an elliptical orbit. Onboard thrusters are then used to circularize the orbit.

This nearly fuel-free method of decelerating a space vehicle could reduce the typical mass of an interplanetary spacecraft by more than half, allowing for a smaller and less expensive launch vehicle and for faster trip times. In fact, aerocapture, when combined with solar electric propulsion technology, enables missions to outer planet destinations that would be impractical using conventional propulsion.

The requirement to slow down a spacecraft by using drag can be achieved in two ways. The craft can be enveloped by a structure and protected by a rigid heatshield or aeroshell. Such rigid aeroshells are a relatively mature technology used on Apollo return, Mars Viking, Pioneer Venus, Galileo, Mars Pathfinder and the Mars Exploration Rovers. Another option is for the vehicle to deploy an aerocapture inflatable deceleration system commonly called a ballute-a combination parachute and balloon

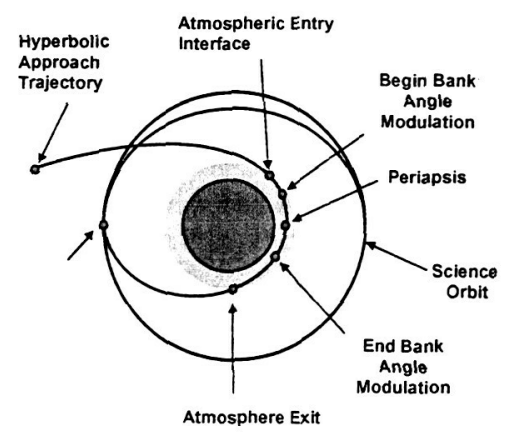

Figure 1 Aerocapture Maneuver made of thin, durable material. 


\section{A. Rigid Aeroshell Investments}

The rigid aeroshell system encases a spacecraft in a protective shell. This shell provides an aerodynamic control surface and a means of protection from the high heating experienced during high-speed atmospheric flight. Once a space vehicle is captured into orbit, the aeroshell is jettisoned.

A traditional aeroshell consists of three main parts: (1) the external thermal protection material; (2) adhesives, which are used to bond the thermal protection system (TPS) to the structure; and (3) an underlying structure to which the internal spacecraft and the external thermal protection material are attached. The challenges to improving this approach are to customize the design and thickness of the thermal protection material to accommodate different heating characteristics endured during aerocapture, and to develop adhesives capable of withstanding extremely high temperatures. Rigid aeroshell systems use lift to change their trajectory during an

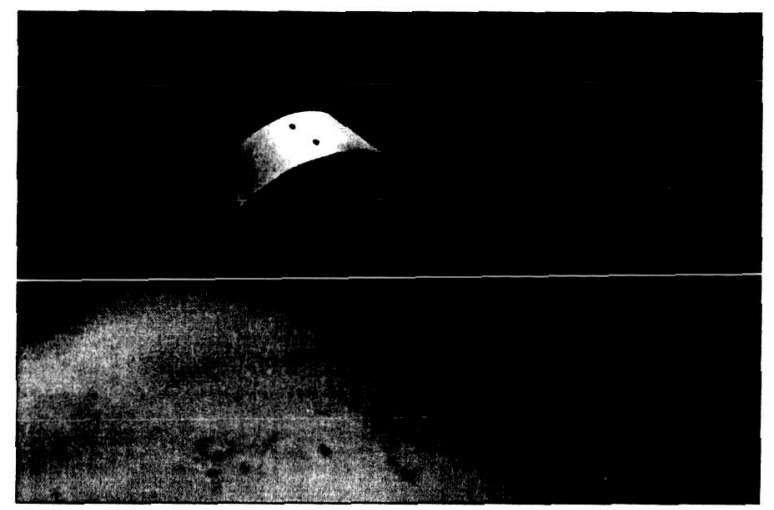

Figure 2 Aerocapture of a Rigid Aeroshell System at Mars

aerocapture maneuver. By flying at trim angle of attack and using bank angle modulation, the vehicle is able to adjust its trajectory and exit the atmosphere at the proper conditions to ensure orbit capture.

In FY2003 NASA awarded five rigid aeroshell technology development contracts as part of the ISPT Cycle 1 NASA Research Announcement (NRA). Cycle 1 investments are developing several alternative approaches to structures and TPS for small body aerocapture missions. These can be combined in different ways for use in different environments. The Cycle 1 investments can be categorized as:

i) "Warm structures" development using new adhesives and resins that allow the bondline (i.e., the interface between TPS and structure) of "traditional" composite structures to go to higher temperatures (from approximately $250^{\circ} \mathrm{C}$ up to $325^{\circ} \mathrm{C}$ or $400^{\circ} \mathrm{C}$ ). In this case, a separate TPS is still bonded to the facesheet of the structure. This work is being performed under two separate awards to the NASA Langley Research Center and Lockheed Martin Astronautics in Denver, Colorado.

ii) "Hot structures" development using Carbon-Carbon (C-C) in new construction methods to improve the heatshield concept used on the Genesis sample return capsule, making the system lighter. In this case, the C-C facesheet sees the heat load and there is no separate TPS bonded to the face of the structure. This work is being performed under an award to Lockheed Martin Astronautics in Denver, Colorado.

iii) Thermal Protection Systems development focusing on detailed response models and material characterization of different TPS systems. This work is being performed under two separate awards to the NASA Ames Research Center and Applied Research Associates in Englewood, Colorado.

iv) Sensors development producing $12-\mathrm{mm}$ diameter by $0.75 \mathrm{~mm}$ thick, lightweight heat flux sensors for use indepth in TPS. The task involves extensive arcjet testing, and integration with different TPS materials. This work is being performed under an award to ELORET Corporation in Sunnyvale, California and the NASA Ames Research Center.

\section{B. Inflatable Decelerator Investments}

The rigid aeroshell is considered the first generation Aerocapture technology. The second generation technology is the inflatable decelerator. The Aerocapture Technology Area is currently investing in three inflatable decelerator systems: the trailing ballute, the afterbody attached ballute, and the forebody attached inflatable aeroshell.

The trailing ballute features an inflated toroid that is much larger than the spacecraft it is towed behind and is used similarly to a parachute to slow the vehicle. The toroid shape was selected to allow the hole in the toroid to "swallow" the spacecraft wake. Approximately 24 hours before the spacecraft interfaces with the planetary atmosphere, the ballute is deployed and allowed to fully inflate. This precludes problems the system would encounter during inflation in the atmosphere. The trailing ballute design allows for easy detachment and minimizes interference with the spacecraft's operation. Trajectory control is simply through drag modulation. When the spacecraft achieves a predetermined deceleration, the ballute is released, allowing the spacecraft to exit the atmosphere. A propulsive periapsis raise maneuver is required to circularize the orbit. The trailing ballute is being developed by Ball Aerospace and Technologies Corporation in Boulder, Colorado under an ISPT Cycle 1 NRA award. 
The afterbody attached ballute is much like the towed ballute except that the ballute is attached directly to the

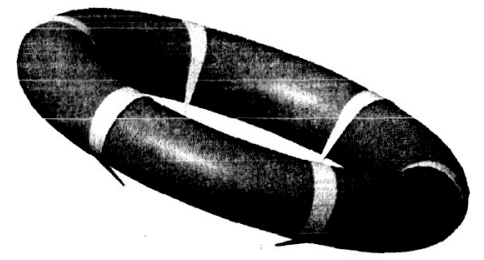

3

Figure 3 Trailing Ballute back of the spacecraft. Again trajectory control is through drag modulation and the ballute is released when a certain deceleration is achieved. The afterbody attached ballute is being developed by Ball Aerospace and Technologies Corporation in Boulder, Colorado under an FY2004 ISPT NRA Cycle 2 award.

The forebody attached inflatable aeroshell is more evolutionary to the rigid aeroshell. The inflatable aeroshell is often referred to as a hybrid system, with a rigid foreshell and an inflated, attached ballute exteñuliug from the front of the spacecraft. Trajeciory conirol for the inflatable aeroshell will incorporate lift and drag, like the rigid aeroshell system; therefore the characterization that the system is more evolutionary than the drag-only modulated systems. The forebody attached inflatable aeroshell is being developed by Lockheed Martin Astronautics in Denver, Colorado as part of an FY2004 Research Opportunities in Space Science (ROSS) Cycle 2 NRA award.

Inflatable decelerator systems provide performance advantages over the rigid aeroshell design. One such advantage is that the payload does not need to be enclosed in a rigid aeroshell system during interplanetary cruise. Eliminating the rigid aeroshell allows the spacecraft payload to take full advantage of the volume available in the launch vehicle shroud due to packaging efficiencies enabled by the inflatable systems. Also, with a rigid aeroshell design, the system must fly low into the atmosphere submitting the spacecraft to significant entry heating, but, with the inflatable decelerator designs, the spacecraft stays very high in the atmosphere where the density is much less and heating can be an order of magnitude (or more) lower, allowing any protection around the payload to be very lightweight.

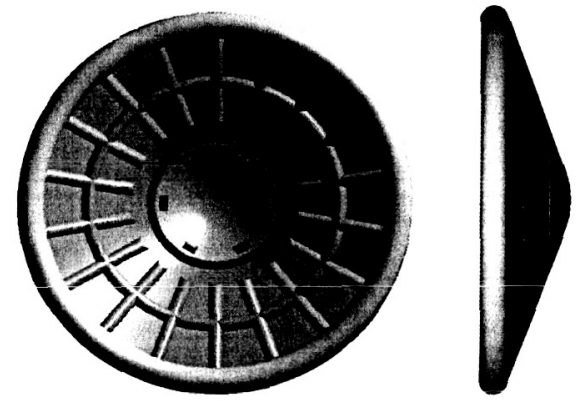

Figure 5. Forebody Attached Inflatable Aeroshell

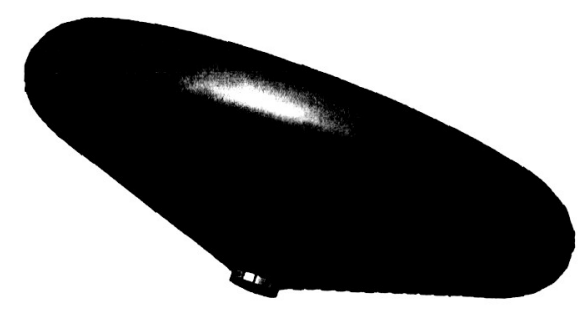

Figure 4 Afterbody Attached Ballute

The Aerocapture Technology Area also leverages the Small Business Innovative Research (SBIR) Program for technology development. Currently the ATA is managing an FY2003 SBIR Phase II award for the development of a raked hypercone concept. This concept is being developed by Vertigo, Incorporated in Santa Cruz, California. This effort is investigating shape morphing the inflatable aeroshell as a means of trajectory control. The ATA is also managing a FY2004 SBIR Phase I award for the development of an "Aeroelastic Simulation Tool for Inflatable Ballute Aerocapture" by CFD Research Corporation in Huntsville, Alabama.

\section{Independent Review of Inflatable Decelerator Investments}

In the summer of 2004 the ISPT Program convened a panel of independent experts to review and assess current inflatable decelerator investments. An independent expert, for the purposes of this review, was defined as an expert not currently being funded by ISPT to participate in inflatable decelerator technology development and not currently working in the same area as a person who was being funded for such. The objective of the review was to assess the Technical Readiness Level (TRL) of inflatable decelerator systems (trailing ballute, afterbody-attached ballute, forebody-attached inflatable aeroshell) for planetary aerocapture at small bodies, to identify the most important subsystem level technologies requiring investment, and to assess the Advancement Degree of Difficulty $\left(A D^{2}\right)$ for each technology. If the $A D^{2}$ was determined to be high or the TRL was determined to be too low, the ISPT Program may have decided to stop investment in inflatable decelerator technology development.

Experts in the fields of thin film material structures, scientific balloon design and development, aerodynamics and aerothermal analysis, trajectory control, and advanced spacecraft propulsion were selected to participate on the panel. 
The panel assessed all three concepts being funded directly by the ISPT but, as the contract for the forebody attached inflatable aeroshell had been awarded late in the summer of 2004, little technology development could be presented for review.

The panel assessed the TRL for each concept and reviewed nine subsystem-level technologies: materials, aerothermodynamics, fluid structure interface, packaging and storage, trajectory control, structural design, manufacturing, tethers, and inflation/deployment. The panel assessed the TRL for the trailing and attached ballute designs to be TRL 3 and the TRL for the more evolutionary inflatable aeroshell to be TRL 4 . The major issues identified by the panel included fluid structure interface modeling and analyses, aeroheating, structural stability and structural adhesives.

Fluid structure interface modeling and analyses had been identified by the inflatable decelerator development teams as a major concern. Tools do not exist to model thin film structures in a rarefied flow and ground test capabilities do not exist to adequately verify all aspects of the modeling performed. Currently teams are approaching the problem by modeling the flowfield and the resulting structural response at one point in time, then iterating to determine the effect of the deformed structure on the flowfield. This interaction continues throughout the aerocapture. Although this is the best approach available, it is time consuming and may not capture all aspects of the interaction. The panel identified this as a top concern and recommended that a tool be developed that could be used by multiple concepts. The CFD Research Corporation tool in development under the SBIR Program is expected to provide a modeling capability but a flight test is considered the only way to verify the modeling performed.

Aeroheating is also a known concern. The panel focused on aeroheating on the tethers of the trailing ballute. The trailing ballute team has since performed more sophisticated analyses of tether heating and has added thermal protection to alleviate the heating effects.

The major structural concern of the panel was buckling of the ballute systems. The internal pressure for the trailing thin film ballute is significantly higher than the maximum dynamic pressure expected upon aerocapture at Titan, but is still much less than 100-Pa. This very low pressure concerned the panel and a recommendation was made to perform more thorough analyses to verify the ballute would not buckle.

During deep-space missions, inflatable decelerators will be exposed to very cold temperatures $\left(-100^{\circ} \mathrm{C}\right)$ for very long periods of time (on the order of $10 \mathrm{yrs}$ ). The panel was concerned that the long term exposure to cold and then the rapid temperature increase to $500^{\circ} \mathrm{C}$ within 10 minutes would present insurmountable challenges to the adhesive systems. The panel recommended performing a comprehensive long term materials test program to identify and address these potential problems.

The panel assessed the $\mathrm{AD}^{2}$ for each of the nine subsystem technologies. The $\mathrm{AD}^{2}$ definitions are included in Table 3. The panel concluded that the $\mathrm{AD}^{2}$ for the technologies needed for inflatable decelerator development were all 2 or less, meaning that the technology challenges could be overcome with a moderate degree of difficulty.

\section{Acknowledgments}

The work described in this paper was funded in whole or in part by the In-Space Propulsion Technology Program, which is managed by the NASA Science Mission Directorate in Washington, D.C., and implemented by the In-Space Propulsion Technology Projects Office at Marshall Space Flight Center in Huntsville, Ala. The program objective is to develop in-space propulsion technologies that can enable or benefit near and mid-term NASA space science missions by significantly reducing cost, mass or travel times.

The authors wish to express our thanks to the Technology Review for Aerocapture Inflatable Decelerators panel members, Dr. Robert Frisbee, Chairman, for their outstanding effort and exceptional support during the review. 
Table 2. Advancement Degree of Difficulty $\left(\mathbf{A D}^{2}\right)$

\begin{tabular}{|c|c|}
\hline AD2 & \multicolumn{1}{c|}{ Description } \\
\hline 1 & $\begin{array}{l}\text { Very low degree of difficulty anticipated in achieving research and development } \\
\text { objectives for this technology; only a single, short-duration technological approach needed to } \\
\text { be assured of a high probability of success in achieving technical objectives in later systems } \\
\text { applications. }\end{array}$ \\
\hline 2 & $\begin{array}{l}\text { Moderate degree of difficulty anticipated in achieving R\&D objectives for this technology; } \\
\text { a single technological approach needed; conducted early to allow an alternate approach to be } \\
\text { pursued to be assured of a high probability of success in achieving technical objectives in } \\
\text { later systems applications. }\end{array}$ \\
\hline 3 & $\begin{array}{l}\text { High degree of difficulty anticipated in achieving R\&D objectives for this technology; two } \\
\text { technological approaches needed; conducted early to allow an alternate subsystem approach } \\
\text { to be pursued to be assured of a high probability of success in achieving technical objectives } \\
\text { in later systems applications }\end{array}$ \\
\hline 4 & $\begin{array}{l}\text { Very high degree of difficulty anticipated in achieving R\&D objectives for this technology; } \\
\text { multiple technological approaches needed; conducted early to allow an alternate system } \\
\text { concept to be pursued to be assured of a high probability of success in achieving technical } \\
\text { objectives in later systems applications. }\end{array}$ \\
\hline 5 & $\begin{array}{l}\text { The degree of difficulty anticipated in achieving R\&D objectives for this technology is so } \\
\text { high that a fundamental breakthrough in physics/chemistry/etc. is needed; basic research in } \\
\text { key areas needed before feasible system concepts can be refined. }\end{array}$ \\
\hline
\end{tabular}

